\title{
Implementation of Short-Pulse Lasers for Wafer Scribing and Grooving Applications
}

\author{
Mathilde Gobet, Samuel Obi, Michaël Pavius, Masaki Takano, Nandor Vago, Kyumin Lee, \\ Yasushi Kozuki, Alexandre Pauchard \\ Synova SA, Chemin de la Dent d'Oche, 1024 Ecublens, Switzerland \\ E-mail:gobet@synova.ch
}

\begin{abstract}
This paper presents micro-machining results obtained by combining a short-pulse $10 \mathrm{~ns}$ green laser with the water jet-guided laser technology. The short pulse duration offers significant advantages for a wide range of applications. Experimental results of semiconductor grooving, edge isolation and P1 fabrication step of thin film solar cells, as well as silicon wafer dot marking, are presented. The study compares the results obtained with short and long pulse lasers.

DOI: $10.2961 / \mathrm{j} 1 \mathrm{mn} .2010 .01 .0004$
\end{abstract}

Keywords: Laser, micro-machining, short pulse, water-jet guided laser, grooving, scribing, edge isolation

\section{Introduction}

The water jet-guided laser technology or Laser MicroJet $^{\circledR}$ (LMJ), first presented in 1994 [1,2], has found a broad range of applications in the precision micro-machining field. It is used today in the semiconductor, solar, electronics, medical, tooling [3], high brightness LED [4], watch and automotive industries.

The principle of the water jet-guided laser technology is to couple a high power pulsed laser beam into a hair-thin, low-pressure water jet. A schematic of the principle is shown in Figure 1.

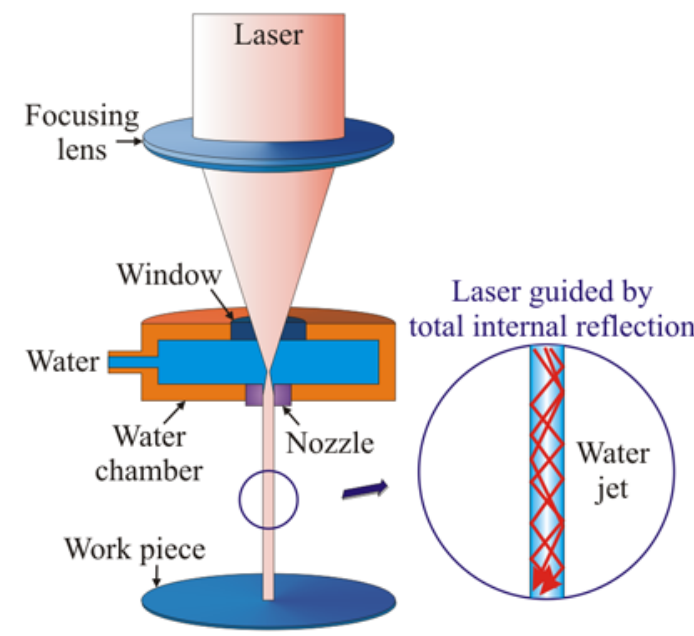

Figure 1: Basic principle of the water jet-guided laser technology

An optical fiber cable transmits the beam of a high power Q-switched diode-pumped solid-state (DPSS) laser to an optical head. There it is focused through a transparent window into a nozzle located at the bottom of a thin waterfilled chamber. Pure de-ionized, degassed and filtered water is introduced into the water-filled chamber with a pressure ranging from 50 to $600 \mathrm{bar}$, depending on the nozzle diameter. Larger nozzle diameters require a smaller water pressure. Typical nozzle diameters range from 20 to 150 $\mu \mathrm{m}$. The cylindrical water jet exiting the nozzle guides the laser beam by means of total internal reflection at the water/air interface, similarly to conventional glass fibers. When it reaches the work piece, the laser ablates the material by melting and vaporization.

The water jet-guided laser technology offers several advantages over the conventional dry laser cutting process. First, because the water jet is cylindrical and the guided laser beam parallel, kerf walls are highly parallel. The jet stable length and hence the working distance can be several centimeters long, depending on the jet diameter. There is thus no need for expensive focus control optics. The largest nozzle diameters used with the Laser MicroJet ${ }^{\circledR}$ process can yield working distances in excess of $15 \mathrm{~cm}$.

Second, the water jet prevents heat damage to the material by cooling the cutting edges in between the laser pulses. Third, contamination is greatly reduced, as the water jet develops a high kinetic energy that efficiently removes the molten material generated by the laser ablation. Contamination by particle deposition is avoided thanks to a thin water film that covers the wafer surface during the cutting process. The particles, already cooled down by the water jet, are unable to adhere to the sample surface.

Another advantage of the water jet-guided laser technology is the negligible mechanical force of the jet onto the wafer, due to the small jet diameter and the low water pressure. This force, smaller than $0.1 \mathrm{~N}$, leaves the material unscathed when exposed to the bare jet. Additionally, the cutting process does not generate chipping or micro-cracks. As a comparison, the assist gas jet used in conventional laser cutting applies a force of about $1 \mathrm{~N}$, ten times higher than the water jet-guided laser. Finally, very low water consumption of approximately $1.2 \mathrm{l} /$ hour is required for $50 \mu \mathrm{m}$ diameter nozzles at a pressure of 300 bar.

Until now the water jet-guided laser technology has predominantly been used with long-pulse lasers, with pulse durations ranging from $100 \mathrm{~ns}$ to $1 \mathrm{~ms}$. In this paper we present micro-machining results obtained with 10 ns pulses from Q-switched frequency-doubled DPSS lasers. The short pulse duration allows reduction of the heat-affected zone close to the laser beam irradiated domain. 
The next section details the characteristics of the laser used for the experiments described in this paper. Sections 3 to 6 present experimental results of silicon carbide grooving, solar cell edge isolation, molybdenum scribing and silicon wafer dot marking. The main motivation for evaluating shorter pulse lasers was to test applications that proved challenging when using longer pulses and to compare the results.

\section{Short-pulse laser description}

The applications presented in Sections 3 to 6 were performed using a compact end-pumped $\mathrm{Nd}: \mathrm{YVO}_{4}$ laser with the fundamental output wavelength of $1064 \mathrm{~nm}$ [5]. A second harmonic generation (SHG) module was appended to the infrared output to obtain $532 \mathrm{~nm}$ green light. The laser produces short 10 ns laser pulses at about $11 \mathrm{~W}$ average output power. The Q-switch repetition rate ranges from 15 to $300 \mathrm{kHz}$. The full angle beam divergence is smaller than 1 mrad, which corresponds to a $\mathrm{M}^{2}$ factor smaller than 1.3. The pulse-to-pulse stability is better than 5\% RMS.

Besides the laser main cavity and SHG, the unit includes a chiller and a power supply. In the latter, two laser diode modules with $26 \mathrm{~W}$ each of $808 \mathrm{~nm}$ pump power are integrated, together with their power supply, fans and control electronics for the laser head and communication. The light from the pump diodes is guided to the main laser cavity using two optical fibers.

At the laser output the beam was focused into a $150 \mu \mathrm{m}$ fiber in order to facilitate the integration with the LMJ optical head. The focusing optics consisted of a beam expander and a focusing lens, mounted outside of the laser chassis.

The laser was characterized at different diode current levels and repetition rates. At maximum diode current level, the average laser power measured at fiber output decreases from $10 \mathrm{~W}$ at $40 \mathrm{kHz}$ to $6 \mathrm{~W}$ at $100 \mathrm{kHz}$. The pulse width at $100 \%$ diode current increases from 9 ns at $40 \mathrm{kHz}$ to 16 ns at $100 \mathrm{kHz}$. The peak power at maximum diode current level varies from $4 \mathrm{~kW}$ at $100 \mathrm{kHz}$ to $26 \mathrm{~kW}$ at $40 \mathrm{kHz}$. The pulse energy at $100 \%$ diode current is $260 \mu \mathrm{J}$ at 40 $\mathrm{kHz}$ and $62 \mu \mathrm{J}$ at $100 \mathrm{kHz}$.

\section{Silicon carbide (SiC) grooving}

Due to its superior properties compared to silicon, $\mathrm{SiC}$ represents a very promising material for high temperature, high frequency and high power applications. Its electric field breakdown strength, approximately ten times larger than silicon, its wide bandgap, its high thermal conductivity together with its high saturated drift velocity, high thermal stability and chemical inertness, constitute numerous favorable properties for high power devices.

The grooving tests were performed on $50 \mu \mathrm{m}$ thick SiC wafer using the Laser Microjet technology. The customersupplied samples were patterned with photoresist and the cuts had to be performed in the lines free of photoresist. Figure 2 shows the photoresist-patterned wafer with the cut groove.

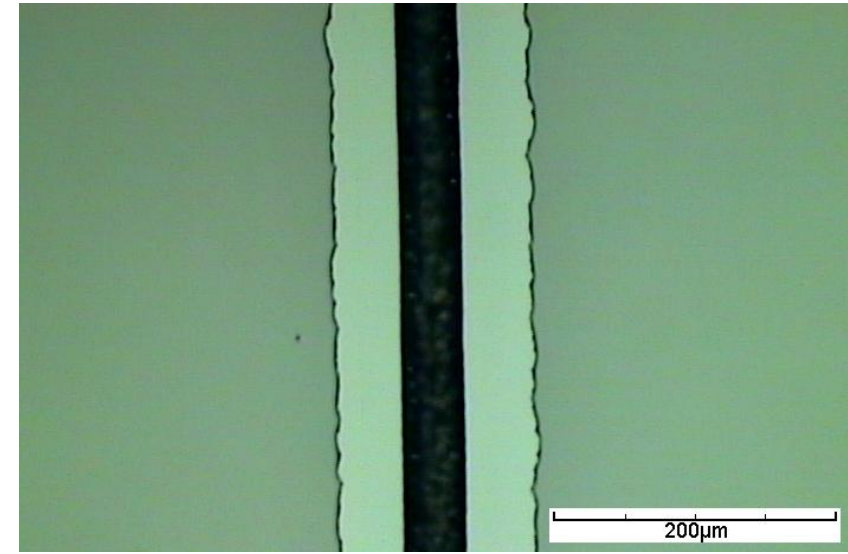

Figure 2: Photoresist-patterned wafer with $20 \mu \mathrm{m}$ deep groove

Figure 3 shows a topside view of the groove under dark field illumination, with focus at the bottom of the groove.

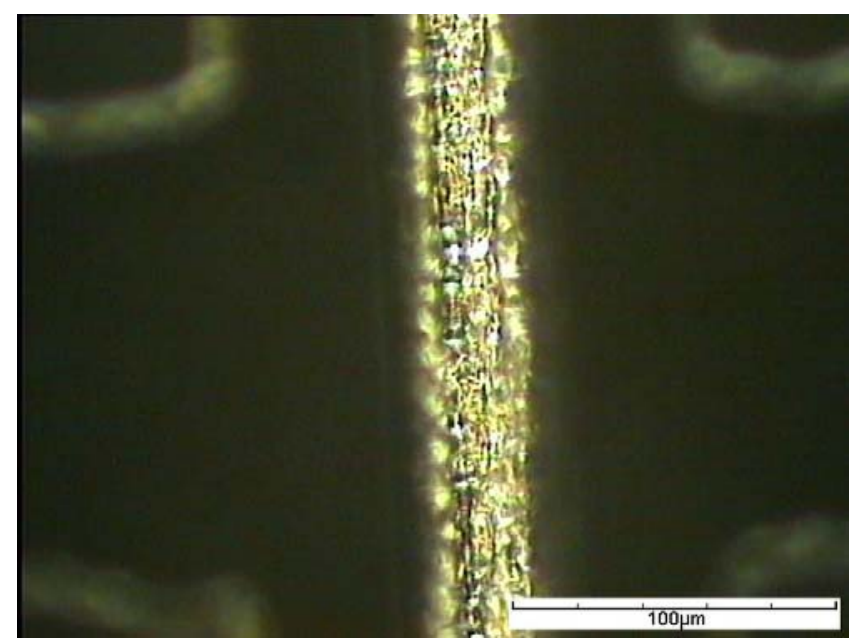

Figure 3: Topside view of the groove (dark field illumination), with focus at the bottom of the groove.

An average power of $10 \mathrm{~W}$ and a repetition rate of 70 $\mathrm{kHz}$ were used. A $48 \mu \mathrm{m}$ groove width and $20 \mu \mathrm{m}$ groove depth were obtained in one single pass with a $50 \mu \mathrm{m}$ diameter nozzle. Very sharp groove edges were defined at a grooving speed of $20 \mathrm{~mm} / \mathrm{s}$.

\section{Solar cell edge isolation}

Edge isolation is a standard step of solar cell production. It consists in scribing a continuous groove along the cell edge to electrically isolate the front and rear surfaces, therefore preventing parasitic shunts. The groove has to be deep enough to provide electrical isolation. Additionally, it should be as narrow and as close to the cell edge as possible to maximize cell efficiency.

Solar cell edge isolation was performed on multicrystalline silicon cells. A $40 \mu \mathrm{m}$ nozzle was used, yielding a microjet diameter of $36 \mu \mathrm{m}$. Cutting speeds ranging from 150 to $300 \mathrm{~mm} / \mathrm{s}$, at $9 \mathrm{~W}$ average power and at $60 \mathrm{kHz}$ repetition rate, led to sharp kerfs without chipping.

Figure 4 shows a topside view of edge isolation performed on a region of a solar cell surface exhibiting negligible surface roughness. The kerf quality is excellent, providing adequate electrical isolation between top and rear surfaces. 


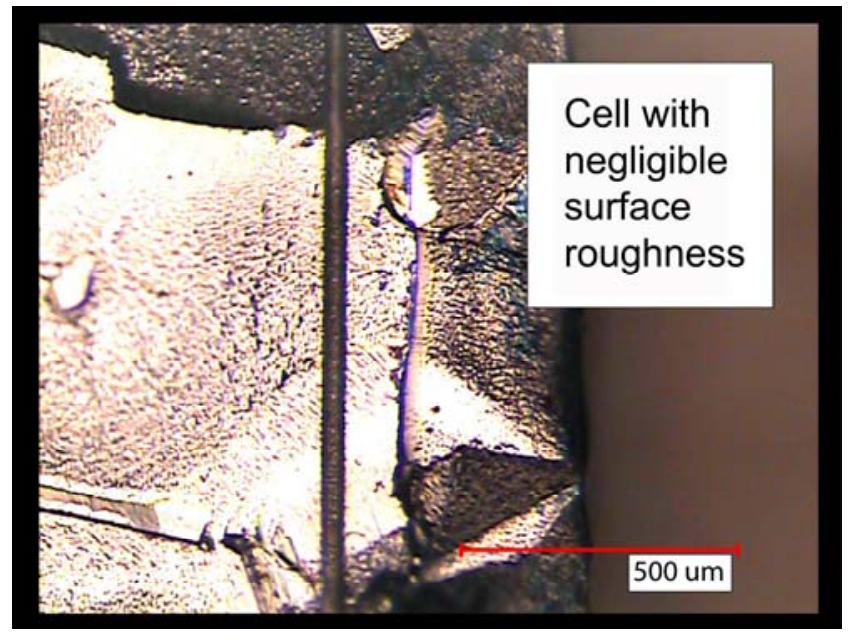

Figure 4: Topside view of solar cell edge isolation

The Laser MicroJet ${ }^{\circledR}$ technology combined with a short-pulse laser enabled successful solar cell edge isolation on surfaces with roughness of $50 \mu \mathrm{m}$. Figures 5 and 6 show topside views of an identical solar cell region, with focus on a flat surface and on the top surface, respectively. The flat surface is defined as the lowest flat cell region, while the top surface refers to the highest cell point.

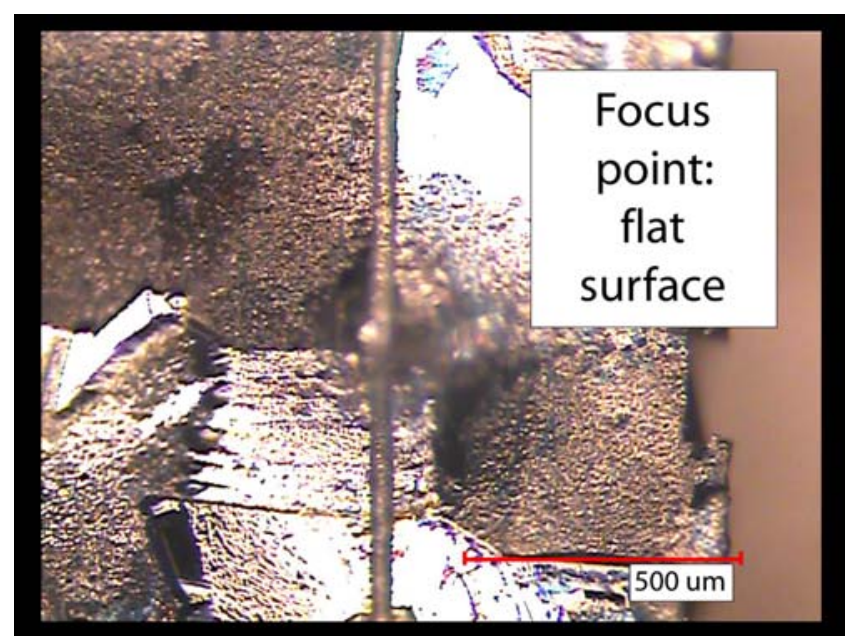

Figure 5: Topside view of edge isolation, with focus on cell flat surface

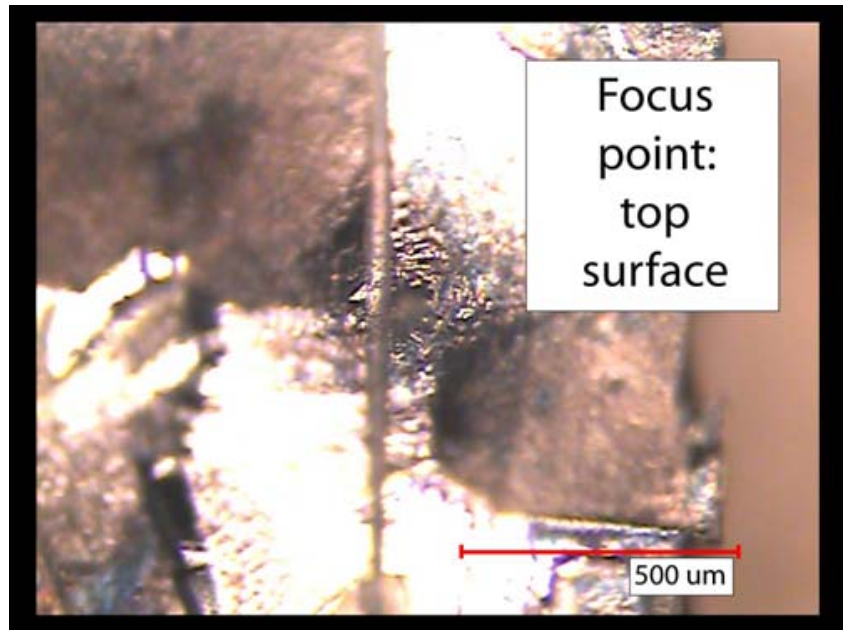

Figure 6: Topside view of edge isolation, with focus on top surface (defined as the highest point of the region surface)
Despite the surface roughness, the cell was grooved in an unbroken line. Successful electrical isolation between top and rear surfaces was achieved for multi-crystalline silicon solar cells with surface roughness of $50 \mu \mathrm{m}$.

\section{Molybdenum scribing: long versus short pulse la-} sers

In the fabrication of thin film solar cell, the scribing of a conductive layer covering the substrate is called P1 step. The scribing of molybdenum on glass was investigated using two $532 \mathrm{~nm}$ Q-switched frequency doubled lasers. A long pulse laser, with pulse durations around 350 ns, and the short pulse laser described in Section 2 were used to process glass wafers with a $500 \mathrm{~nm}$ Mo top layer.

Figure 7 shows scribing of Mo using a long pulse laser, at $15 \mathrm{~W}$ average power and $50 \mathrm{kHz}$ repetition rate. Figure 8 depicts scribing results using the short pulse laser, at $14 \mathrm{~W}$ average power and $40 \mathrm{kHz}$ repetition rate. For both experiments the cutting speed was set to $1000 \mathrm{~mm} / \mathrm{s}$. Average powers represent in this case the laser power at laser output before the optical fiber. Laser stability issues of the long pulse green laser at low average powers resulted in alternating smaller and larger craters. The larger craters are clearly visible in Figure 7. High electrical resistance of samples shown in Figures 7 and 8 confirmed the absence of bridges between the two regions.

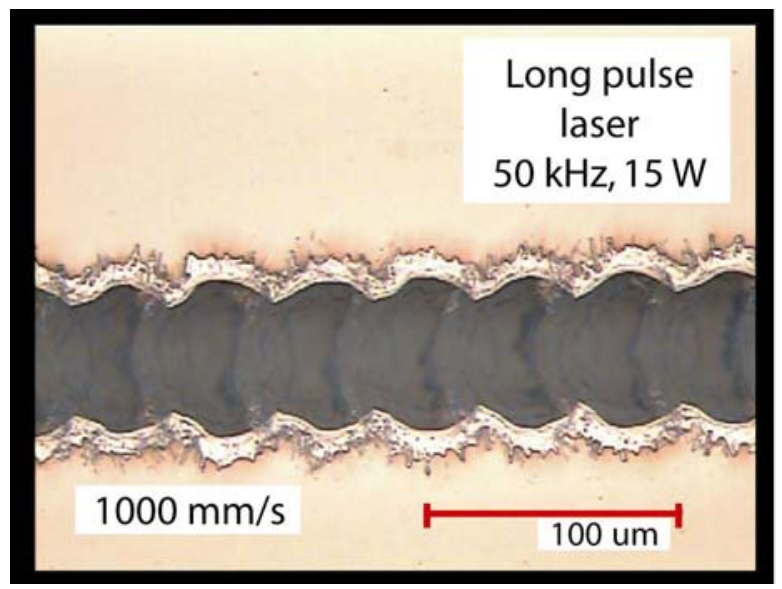

Figure 7: Groove scribed with long pulse laser, at $1000 \mathrm{~mm} / \mathrm{s}$ cutting speed

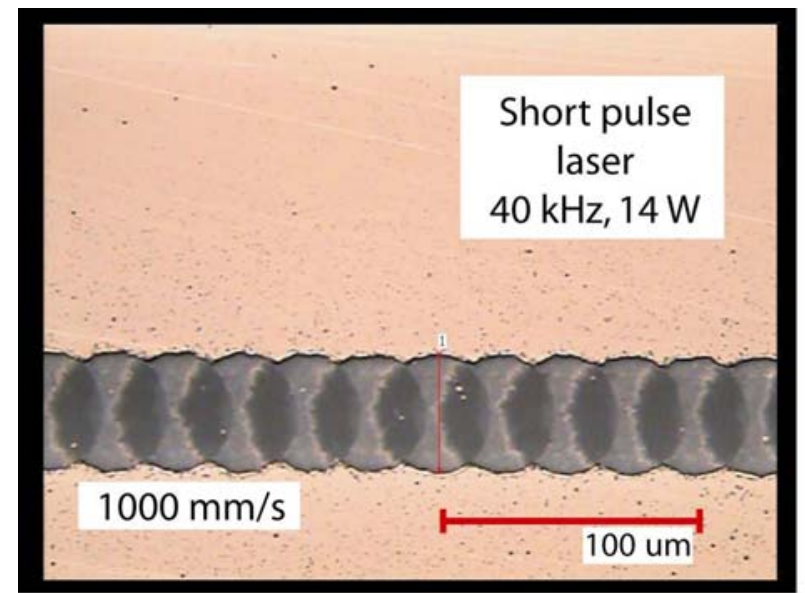

Figure 8: Groove scribed with short pulse laser, at $1000 \mathrm{~mm} / \mathrm{s}$ cutting speed 
The wafer scribed with the short pulse laser exhibit significantly better cutting quality, with a sharp kerf and the absence of burrs. Figures 9 and 10, corresponding to Mo scribing with long and short pulse lasers, exhibit comparable kerf quality at cutting speeds of 100 and $1000 \mathrm{~mm} / \mathrm{s}$, respectively. Short pulse laser scribing thus provides ten fold cutting speed increase at similar cutting quality.

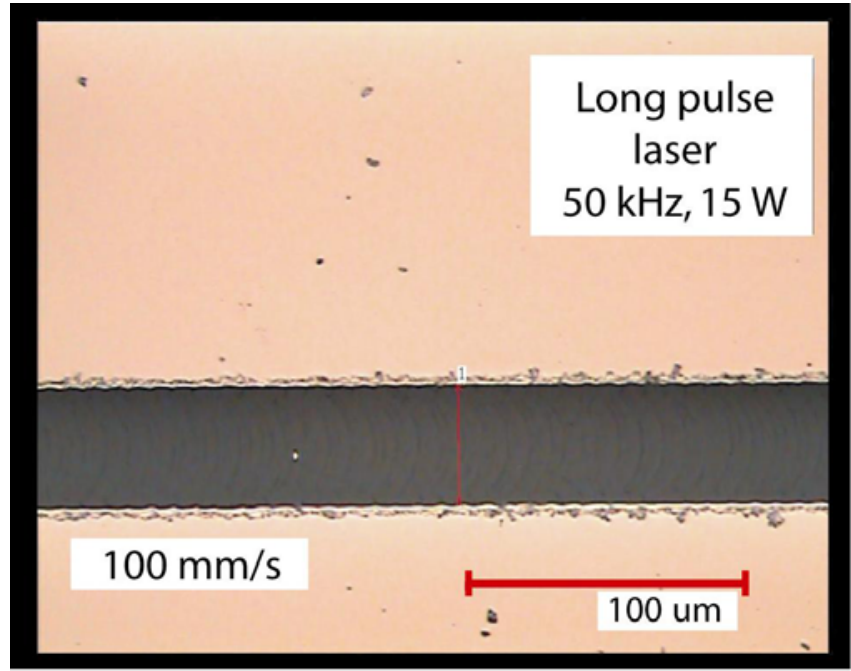

Figure 9: Groove scribed with long pulse laser, at $100 \mathrm{~mm} / \mathrm{s}$ cutting speed

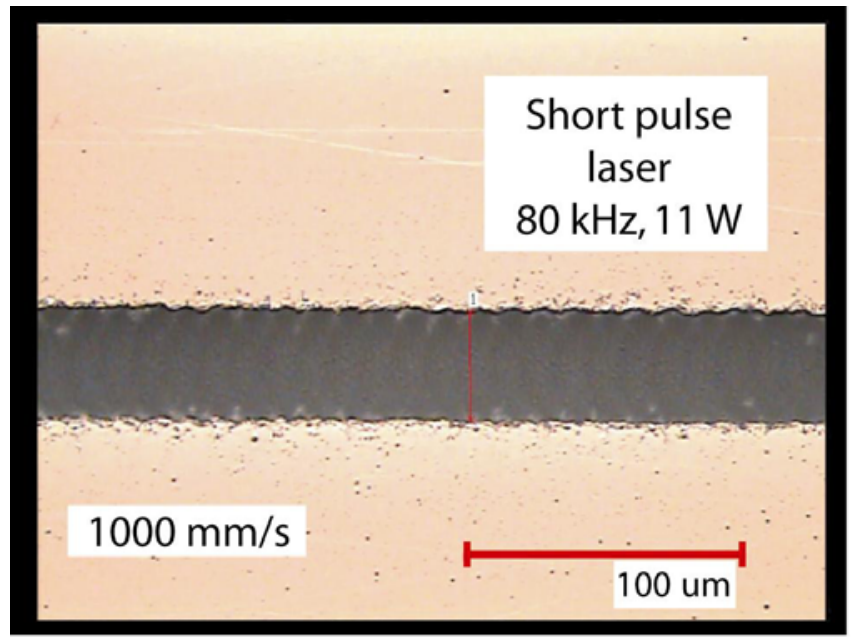

Figure 10: Groove scribed with short pulse laser, at $1000 \mathrm{~mm} / \mathrm{s}$ cutting speed

All samples pictured in Figures 7 to 10 showed high electrical resistance, indicating that the Mo was successfully removed in all cases.

\section{Si wafer dot marking: long versus short pulse lasers}

Laser dot marking is an efficient way to add permanent marking on integrated circuits, micro-electro-mechanical systems or solar cells. The Laser MicroJet technology has been tested for dot marking on silicon wafers using two $532 \mathrm{~nm}$ Q-switched frequency doubled lasers. A long pulse laser, with pulse durations of 100 to 200 ns, and the short pulse laser described in Section 2 have been used to process $670 \mu \mathrm{m}$ thick silicon wafers.

Figures 11 and 12 show holes drilled using a long pulse laser and a $70 \mu \mathrm{m}$ nozzle. At $30 \mathrm{kHz}$ repetition rate and $22 \mathrm{~W}$ average power, a groove depth of $30 \mu \mathrm{m}$ was achieved. Material re-deposition is encountered at the edge of every drilled hole.

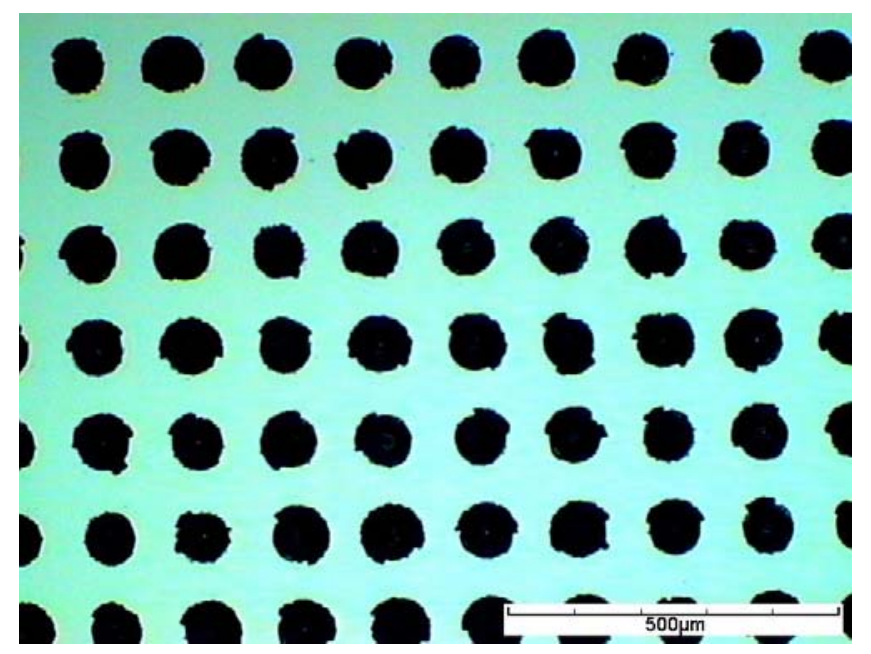

Figure 11: Topside view of holes drilled using a long pulse laser

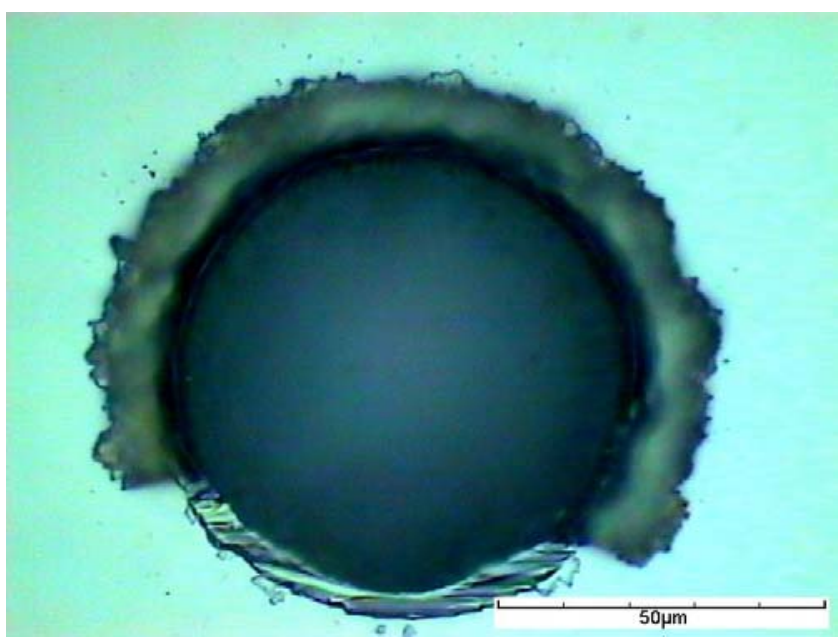

Figure 12: Hole drilled using a long pulse laser

The silicon wafers were subsequently processed with the short pulse laser described in Section 2, using a laser repetition rate of $70 \mathrm{kHz}$ and an average power of $7 \mathrm{~W}$. Dots with a diameter of 50 to $100 \mu \mathrm{m}$ were drilled. Figure 13 shows a close-up view of a drilled hole under bright field illumination. 


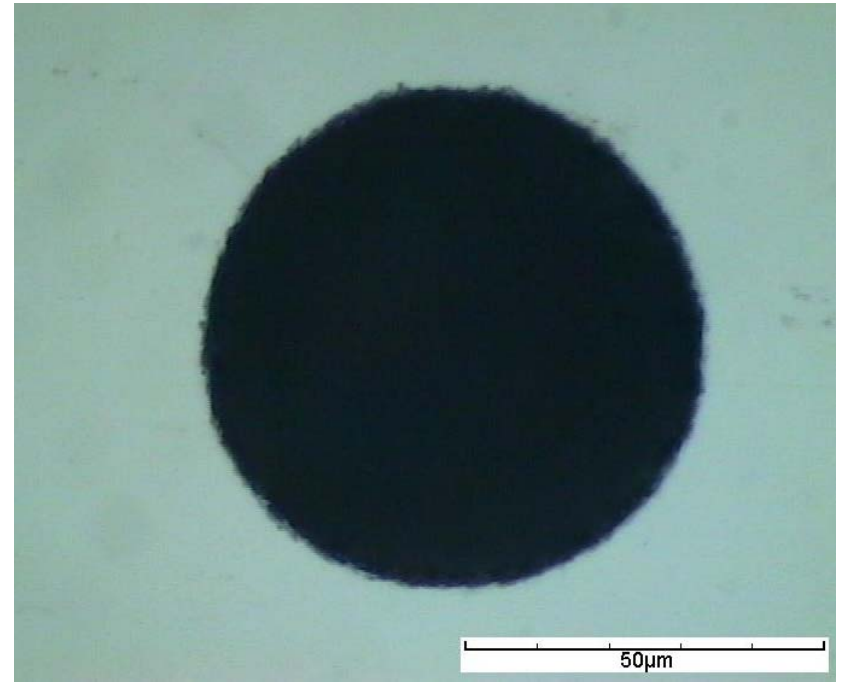

Figure 13: Hole drilled using a short pulse laser (bright field illumination)

The depth of the holes was varied from 30 to $130 \mu \mathrm{m}$ by changing the processing conditions. A speed of $2.2 \mathrm{~ms}$ (5.1 ms) per hole was obtained for $30 \mu \mathrm{m}$ (70 $\mu \mathrm{m}$, respectively) deep holes. The hole-to-hole depth uniformity is excellent, as shown in Figure 14.

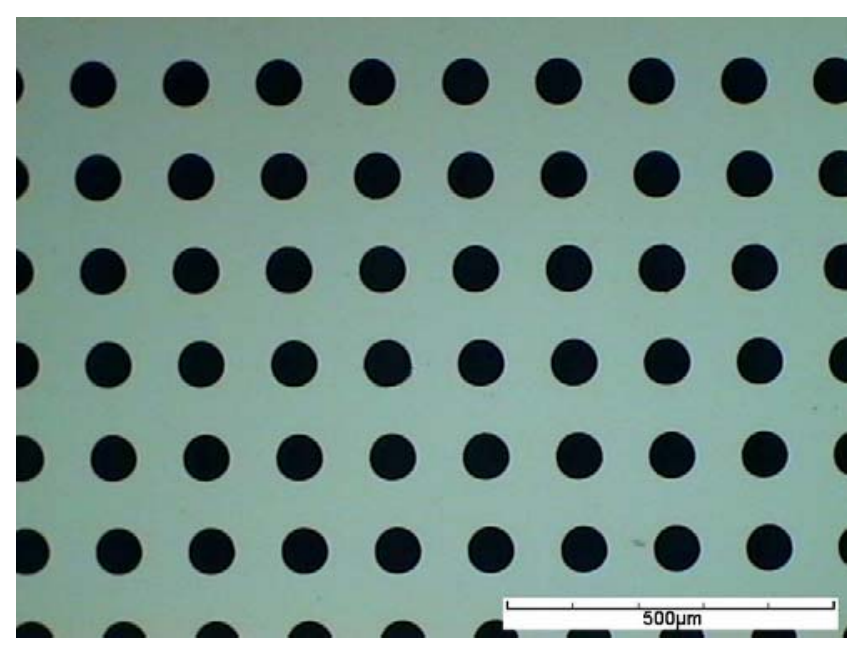

Figure 14: Topside view of holes drilled using a short pulse laser (bright field illumination)

\section{Conclusions}

In this paper, results obtained by combining the water jet-guided laser technology with a short-pulse (10 ns) green laser are presented. We demonstrated that short-pulse lasers are very interesting for precision grooving and scribing applications. The technology is well suited for $\mathrm{SiC}$ grooving, the P1 fabrication step of thin film solar cells, edge isolation and Si wafer dot marking. The kerf quality is excellent, without any chipping and burrs. Superior scribing and grooving qualities were demonstrated compared to long pulse laser scribing and grooving.

\section{References}

[1] B. Richerzhagen, "Development of a System for Transmission of Laser Energy," Ph. D. Thesis work, EPFL, Switzerland, 1994

[2] B. Richerzhagen, G. Delacrétaz, R.P. Salathé, "Complete Model to Simulate the Thermal Defocusing of a Laser Beam Focused in Water," Optical Engineering, vol. 35, No. 7, pp. 2058 - 2066, 1996

[3] A. Pauchard, M. Di Marco, B. Carron, G. Suruceanu, B. Richerzhagen, A. Brulé, Notker Kling, "Recent developments in the cutting of ultra hard materials using water jet-guided laser technology”, ALAC 2008 conference proceedings, 2008

[4] A. Pauchard, A. Spiegel, B. Richerzhagen, "Dicing of HB-LED devices embedded in copper or copper tungsten substrates", ICALEO 2008 conference proceedings, 2008

[5] Hippo-532QW laser from Newport/Spectra Physics, http://www.newport.com

(Received: July 7, 2009, Accepted: December 14, 2009) 